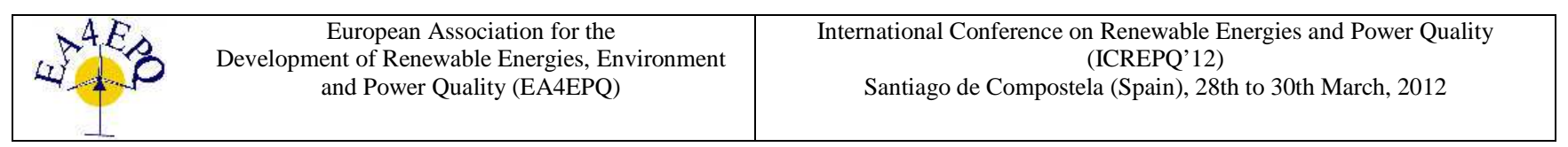

\title{
New aspects regarding the modernisation of High Power Laboratory of ICMET-Craiova to attain the technical and qualitative level corresponding to European Union requirements
}

\author{
Dr. Eng. George CURCANU, Eng. Constantin ILINCA, Eng. Corneliu CHICIU \\ R\&D National Institute ICMET-Craiova, 118A Decebal Blvd, 200746 Craiova, Romania \\ phone: +40351 402427; +40351404 888; +40351404889 \\ fax: +40351404890; +40251415482 \\ http://www.icmet.ro,email: LMP@icmet.ro
}

KEYWORDS: electromagnetic fields, tests, standards, data acquisition and processing

\begin{abstract}
High Power Laboratory is designed for high currents tests and it found within a modernisation process through: purchasing of new equipment, electrical apparatus and electromechanical equipment in order to realise a new installation endowed with equipment having superior characteristics and by rehabilitation of the existent buildings according to European Union norms.
\end{abstract}

\section{Introduction}

Within a project with European funding was aimed the endowment of High Power Laboratory with modern electric equipment and apparatus specific to researchdevelopment domain with the aim to converge with European economic space, such that to attain the technical level of other similar laboratories from Europe. Through this will be created services of high scientific and technical competence related to the development of a durable partnership with international economical medium $[1,2,4]$.

For modernisation of High Power Laboratory (HPL) was proceeded to:

- modernisation of laboratory building through rehabilitation of existing spaces

- achievement of electrical equipment and apparatus realised with high technology

- modernisation of existing equipment and apparatus through replacement or completion with others new ones

These actions were performed with respect of no environment pollution conditions and the new equipment, apparatus and machineries will contribute to reduce the electromagnetic perturbations with full safety conditions.

\section{Description of HPL installations}

HPL is a very complex installation composed from several subassemblies with specific elements to testing circuit, located within special arranged spaces.

\subsection{Laboratory building modernization}

The voltage supply consists of three motor-generator groups together with auxiliary equipment like: starting station, greasing station, $6 \mathrm{kV}$ and $0.4 \mathrm{kV}$ station, DC batteries station etc. located in corresponding arranged rooms. Thus, generator circuit-breakers and synchronisation switches are located in other special arranged room, reactors and $12 \mathrm{kV}$ distribution bars are located within $12 \mathrm{kV}$ room, short-circuit and voltage adjustment transformers are placed within transformers room, TRV adjustment elements and voltage dividers are located within $150 \mathrm{kV}$ room, tested switching apparatus and current transducers are located within testing cells etc. The control of command, signalising and protection circuit is placed within electric command room and the control and command of tests are placed within command and observation room.

All these spaces were modernised through constructive rehabilitation, using modern materials.

\subsection{New equipment endowment}

New achieved equipment and apparatus have the aim of:

- modernization of measuring and recording circuits

- modernization of electrical systems

- modernization of electromechanical equipment used for testing circuit preparation

\subsubsection{Measuring circuit:}

- Voltage dividers $120 \mathrm{kV} / 60 \mathrm{~V}$ and $1500 \mathrm{~V} / 50 \mathrm{~V}$

- Rogowski coils: 6 kA, 12 kA, 300 kA

- $\quad 12 \mathrm{kV}$ voltage and current transformers

- Standard transformers 
- Optoelectronic travel transducers

- Transducers for dynamic pressure measurements

- Transducers for electro-dynamic force measurements

- High speed camera: 40000 frames/second

- Wireless network

- Fiber optic intranet network with 10 terminals

- Data acquisition and processing systems with optical insulation: Transient-recorder $100 \mathrm{MS} / \mathrm{s}, 16$ bit, 1 GB Memory/channels, 24 channels

\subsubsection{Monitoring system:}

- $\quad$ Electric motors windings temperature monitoring

- Monitoring of technical condition of circuit-breakers

- Supervision of HPL systems

- Ground sockets check device

- Check of the dielectric strength of transformers oil

\subsubsection{Electromechanical equipment:}

- Compressors

- Forklifts

- Jacks

- Tractor basket

\subsection{Modernisation of existing equipment}

The installation of HPL was modernised by endowment with new equipment and apparatus realised with new technology, such that:

- $\quad 0.4 \mathrm{kV}$ station:

$$
\begin{array}{ll}
\circ & \text { contactors } \\
\circ & \text { disconnectors } \\
\circ & \text { fuses }
\end{array}
$$

- $6 \mathrm{kV}$ station:

$\begin{array}{ll}\circ & \text { vacuum circuit-breakers } \\ \circ & \text { disconnectors } \\ \circ & \text { fuses } \\ \circ & \text { energy meters }\end{array}$

- Generator control, protection and signalising circuit:

$$
\begin{array}{ll}
\circ & \text { protection relays } \\
\circ & \text { contactors } \\
\circ & \text { voltmeters and ammeters }
\end{array}
$$

- Testing circuits:

$$
\begin{array}{ll}
\circ & \text { MV and HV bus bars } \\
\circ & \text { LV and HV power transformers } \\
\circ & \text { capacitors }
\end{array}
$$

- Temperature-rise stand:

$$
\begin{array}{ll}
\circ & \text { bridge controlled rectifiers } \\
\circ & \text { power transformers } \\
\circ & \text { LV contactors } \\
\circ & \text { LV circuit-breakers }
\end{array}
$$

\section{Particularities regarding testing and measuring circuit}

Testing circuit from High Power Laboratory of ICMET Craiova uses a direct scheme. [2,3,7] As resulting from standards requirements (Figure 1), main testing and measuring circuits were modernised with new apparatus, equipment, measuring and recording devices which avoid negative effects on environment and those of electromagnetic fields on staff. [3,4]

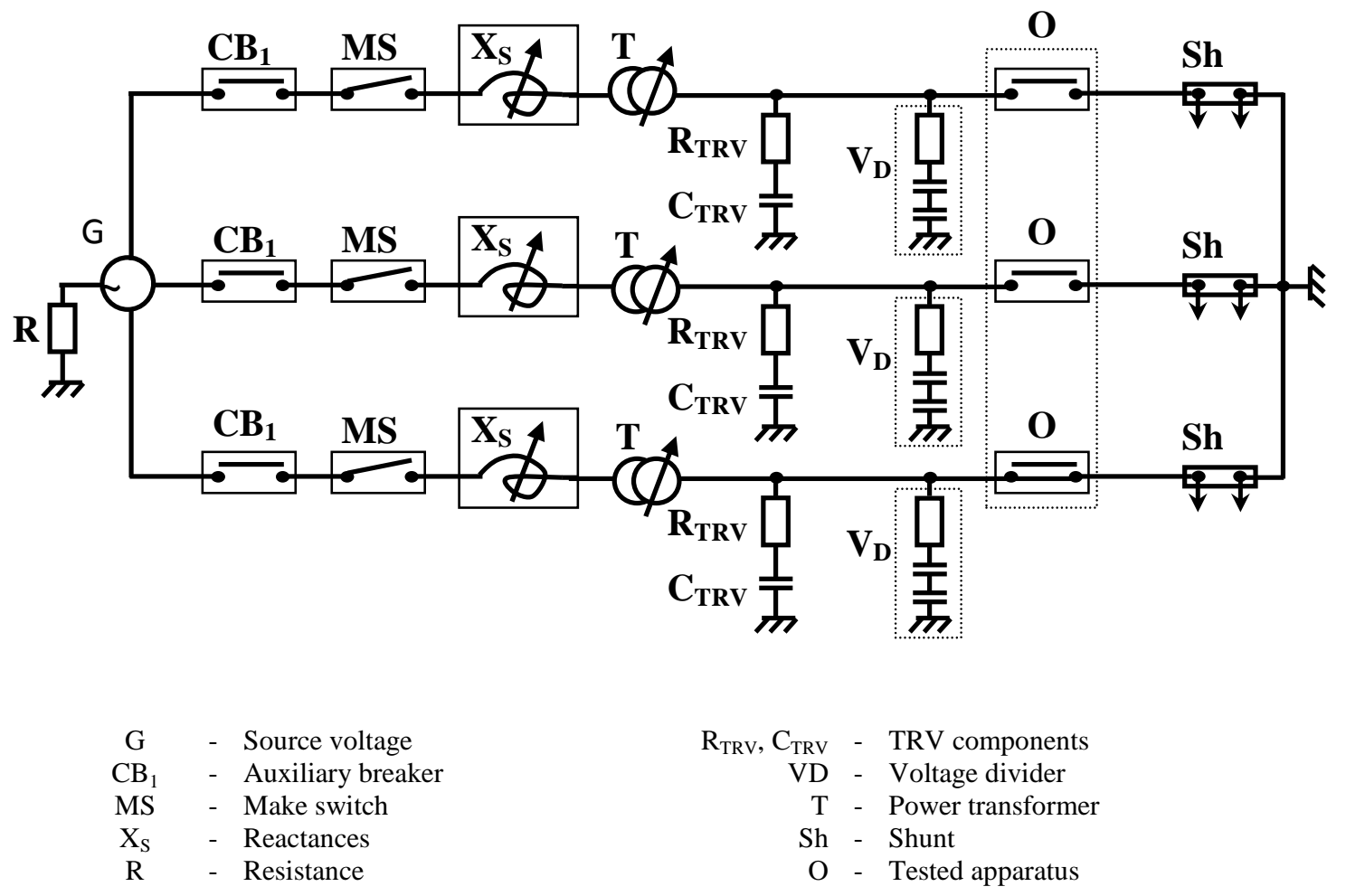

Figure 1 - Test circuit diagram 


\subsection{Testing circuits}

Vacuum circuit-breakers from $6 \mathrm{kV}$ supply voltage (12 kV/1250 A, $12 \mathrm{kV} / 2500 \mathrm{~A})$ were chosen to replace minimum-oil circuit-breakers which presented fire risks and pollution by explosion and SF6 circuit-breakers also have negative environment impacts due to gas losses. [3] Vacuum circuit-breakers have not any damaging influence on environment and no explosion risks. Reduced number of components and simplified construction made them more compact and with reduced dimensions which offer them better maintenance and longer life duration (over 25 years).

$0.4 \mathrm{kV}$ supply voltage contains low voltage equipment like: circuit-breakers (400 V/2000 A), circuit-breakers (400 V/100, 200, 300, $400 \mathrm{~A})$, disconnectors (400 V/200, $500 \mathrm{~A})$, low voltage fuses $(400 \mathrm{~V} / 50 \div 500 \mathrm{~A})$.

Medium voltage busbars system is passed by short-circuit currents up to $100 \mathrm{kA}$ for $1-3 \mathrm{~s}$ duration. In order to reduce the strong electrodynamic stresses due to shortcircuit currents was realised a special construction using screened aluminium busbars.

Reactance coils are of cylinder modular type $(0.1 \Omega /$ $12 \mathrm{kV} / 10 \mathrm{kA}$ ) and are realised from copper bands with special resin insulation. Their horizontal placement with frontal output diminishes the effect of mutual inductances and offers a good stability at electrodynamic stresses. $[2,4]$. The capacitors $(6.4 \mu \mathrm{F} / 12 \mathrm{kV})$ from load circuit are realised with modern technologies with ecologic dielectric replacing the old ones with oil dielectric which creates fire risk through explosion. [3]

For measuring test voltages and transient recovery voltages there are used capacitive dividers: $120 \mathrm{kV} / 60 \mathrm{~V}$, $0 \div 3 \mathrm{MHz}$ bandwidth, waterproof varnished fiber glass cylinder.

\subsection{Measuring circuits}

The distortion of useful signal through interference with several perturbations occurs either at measuring transducer, either at connection cable between measuring transducer and recording system. Perturbations can occur due to electromagnetic fields penetration within measuring circuits, formation of closed current loop, multiple reflections, parasite capacitances, intrinsic inductances, too long measuring chain etc. $[1,2,4]$

As high currents transducers there are used compensated coaxial cage shunts $(2 \mathrm{kA} / 2 \mathrm{~V}-180 \mathrm{kA} / 1.8 \mathrm{~V})$. For rapid variable (like making-breaking currents) are used compensated non-inductive shunts. For circuits with no earthing point are used Rogowski coils $(2 \mathrm{kA}-180 \mathrm{kA}$, $0.3 \div 10 \mathrm{MHz}$ bandwidth).

Other perturbation source is given by closed loop through earthing points. For a testing laboratory is not permitted to have two different grounding points which generate leak currents due to potential differences between these different points and due to voltages induced by rapid variable magnetic fields. So measuring devices (shunts, dividers, recording devices) are connected to same earthing point.

Another perturbation source is given by multiple reflections which appears on long connection cables between transducers and recording devices.
Also for external measurements (test cells) appear influences from local radio and TV emissions. In this case are performing screenings and adaptation using adapting impedances.

When TRV is measuring, perturbations appear from intrinsic inductances and parasite capacitances.

To avoid them there are used capacitive dividers with adapting resistances. Also perturbations can appear from too long measuring cables. In this case there are used coaxial double screened (screen earthed) cables. Some cases it is used differential measure schemes. [1]

Measuring circuits connected to recording devices (transient-recorders) are placed perpendicular to high current path and situated in a screened control room. The supply of transient-recorder is performed through galvanic insulated transformer or screened transformer.

These particular aspects were shown related to modernise of measuring circuits using fiber optic connections and transient-recorders with many channels for automatic data recording and processing (Figure 2). [3,7]

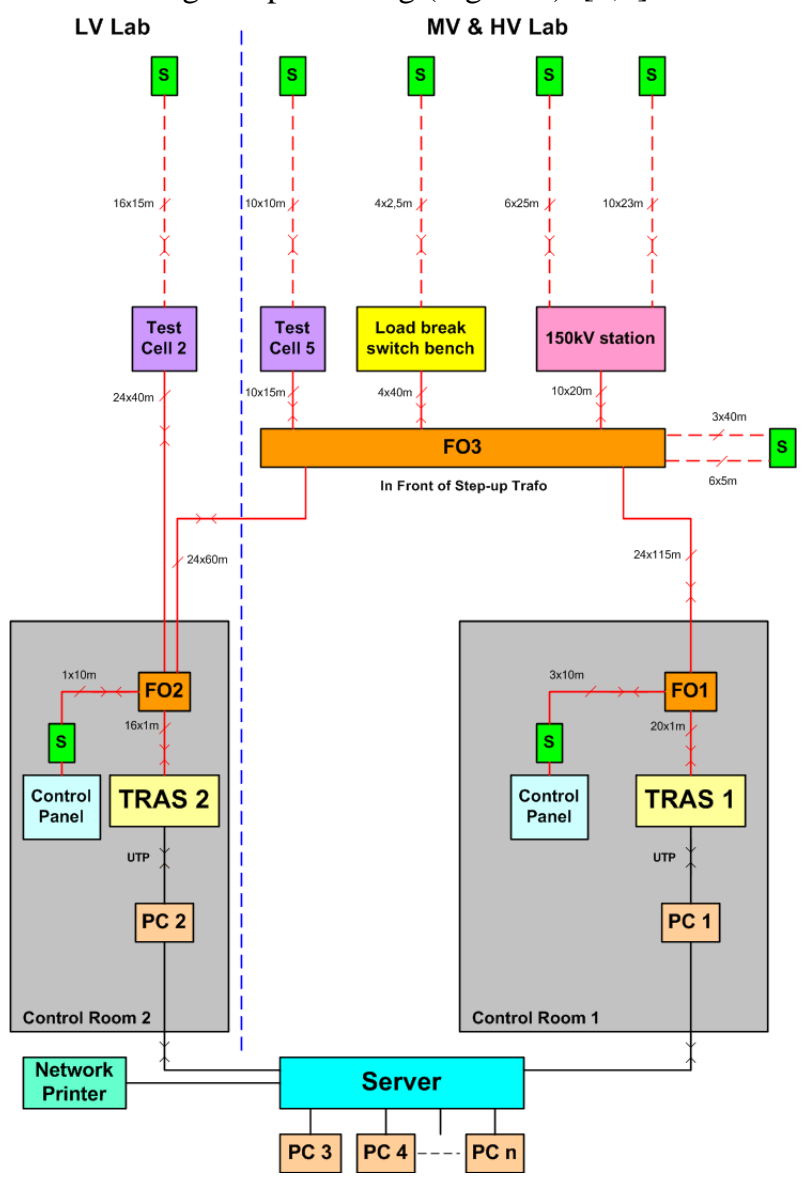

TRAS1,2 - Transient-recorders

FO1,2,3 - fiber optic concentrator and switches (patchfield)

$\mathrm{S}$ - remote module (digitizer)

PC1 ... PCn - local computers

LV Lab - low voltage laboratory

MV Lab - medium voltage laboratory

HV Lab - high voltage laboratory

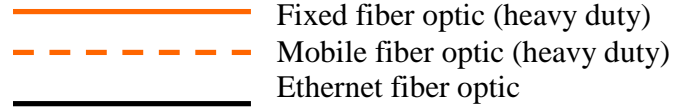

Figure 2 - High Power Laboratory Measuring System 


\subsection{Particularities regarding professional staff}

Laboratory staff are entering testing and measuring circuits only within test responsible witness. There are acoustic and optic warning systems during the tests. Staff is protected during tests within control rooms and is not exposed to electromagnetic fields or to possible explosions of tested apparatus.

However operative witness staff can feel the effects of electromagnetic fields.

In this aspect were established maximum values of exposure at short time electromagnetic fields. [1,5,6] Communication between control room, machines room and circuit preparing staff is performed through digital wireless interphones.

\section{Conclusions}

By modernisation measures of High Power Laboratory on the basis of European funds [2] there were solved the problems related to screening both testing and measuring circuits.

In this aspect the most important it is implementation of a new recording and measuring system by using - in measuring chain - new devices as fiber optic, optical emitters and receivers, transient recorders etc. which ensure both galvanic separation and electromagnetic perturbations immunity (as original contribution).

Also the HPL building was modernised in order to fulfil the conditions of phonic, electromagnetic and environment no pollution [7].

\section{REFERENCES:}

[1] Titihazan V; Negru V; Crisan S; Curcanu G; Titihazan M - Problems of electromagnetic compatibility in high voltage and high power laboratories - Analele Universitatii Oradea, 2002.

[2] Curcanu G - Testing and diagnosis of electric equipment and apparatus at high currents Editura SITECH, Craiova, 2000.

[3] $* * *$ - Modernization of High Power Laboratory (LMP) to reach technical and qualitative level corresponding to European Union requirements - POS CCE - AXA II Project no. 86, 2009.

[4] Chiciu C, Ilinca C, Curcanu G - High Power Laboratory and its role in the development of high voltage apparatus - National Symposium of High Voltage Techniques, Craiova, 2001.

[5] *** - Guide pour l'etablissement de limites d'exposition aux champs electriques, magnetiques, electromagnetiques, champs alternatifs de frecquence variable dans le temps jusqu'à $300 \mathrm{GHz}$ - ICNIRD - International Commission on Non-Ionising Radiation Protection, 2001.

[6] Curcanu G, Ionescu H, Truta D, Chiciu C Aspects regarding modernization of High Power Laboratory for limiting the effects due to electromagnetic fields according to EMC requirements - CNE Proceedings Conferences, Neptun, Romania, 2010.

[7] Curcanu G, Chiciu C, Ilinca C, Ionescu H - Modernisation of High Power Laboratory to fulfill the technical and qualitative conditions for tests according to standards in force ICREPQ'11, Las Palmas de Gran Canaria, Spain, April 12-15, 2011. 